\title{
Ultrasonography of the non-traumatic lesions of the fingers. Pictorial essay.
}

\section{Daniela Fodor, Andreea Lungu}

$2^{\text {nd }}$ Internal Medicine Department, "Iuliu Hațieganu" University of Medicine and Pharmacy, Cluj-Napoca, Romania

\section{Abstract}

The purpose of this pictorial essay is to illustrate the ultrasonographic aspects of the non-traumatic lesions of the fingers. Diffuse (especially dactylitis) and localized (tumors, tophi, calcinosis, etc) lesions of the digits are discussed and illustrated. For a better understanding, the US images are compared with the clinical aspect of the pathological fingers.

Keywords: ultrasonography, fingers, non-traumatic lesions

The development of the high-resolution transducers has increased the performance of ultrasonography (US) in detecting subtle pathological changes in the superficial structures of the musculoskeletal system. For a complete and detailed US evaluation of the fingers $15-18 \mathrm{MHz}$ transducers are required, especially small size transducers (preferable hockey-stick transducer). The normal tendons, joints, ligaments, nerves, vessels, or nails can be accurately imaged (fig 1-4) and the anatomical variants or the different findings of the disorders affecting the digits can be identified.

Apart from the traumatic lesions, commonly found in fingers and toes, the non-traumatic lesions frequently represent a challenge for the clinician. Despite of the easy clinical examination of the digits, the use of the imaging techniques is required to establish the nature and the extension of the underlying pathological process. On behalf of these needs, US is an accessible, quickly performed, and a powerful diagnostic tool for studying disorders which involve different tissues, from the most

Received 15.03.2012 Accepted 30.03.2012

Med Ultrason

2013, Vol. 15, No 2, 147-153

Corresponding author: Daniela Fodor, $\mathrm{MD}, \mathrm{PhD}$

$2^{\text {nd }}$ Internal Medicine Department

"Iuliu Haţieganu" University of Medicine and Pharmacy, Cluj-Napoca, Romania 2-4 Clinicilor str, 400006 Cluj Napoca, Romania Phone: 0040264 591942/442

Email: dfodor@umfcluj.ro

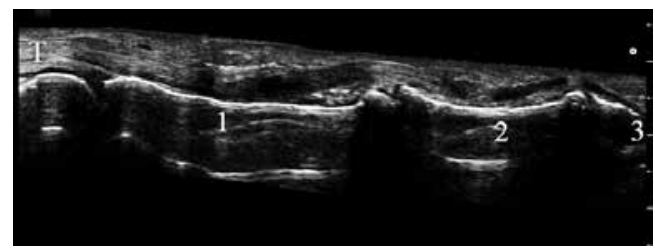

Fig 1. Panoramic view of the normal finger, palmar scan. $1-1^{\text {st }}$ (proximal) phalanx, $2-2^{\text {nd }}$ (middle) phalanx, $3-3^{\text {rd }}$ (distal) phalanx, T- flexor tendon

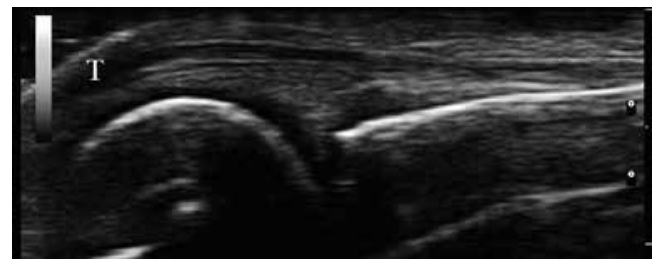

Fig 2. Longitudinal scan of the metacarpophalangeal joint. $\mathrm{T}-$ extensor tendon

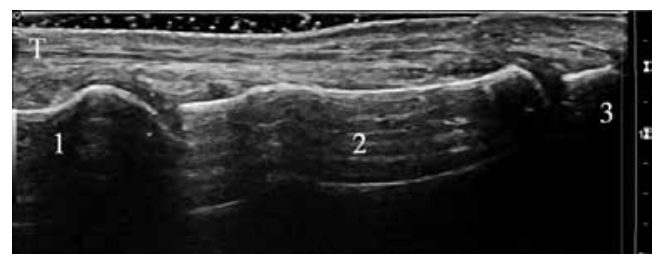

Fig 3. Longitudinal scan of the normal thumb. $1-$ metatarsal bone, 2 - proximal phalanx, 3 -distal phalanx, $\mathrm{T}-$ extensor tendon 


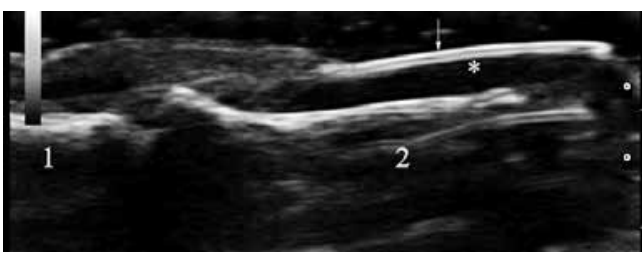

Fig 4. Longitudinal scan of the normal nail. 1 middle phalanx, 2 - distal phalanx, arrow - nail plate, star - nail bed

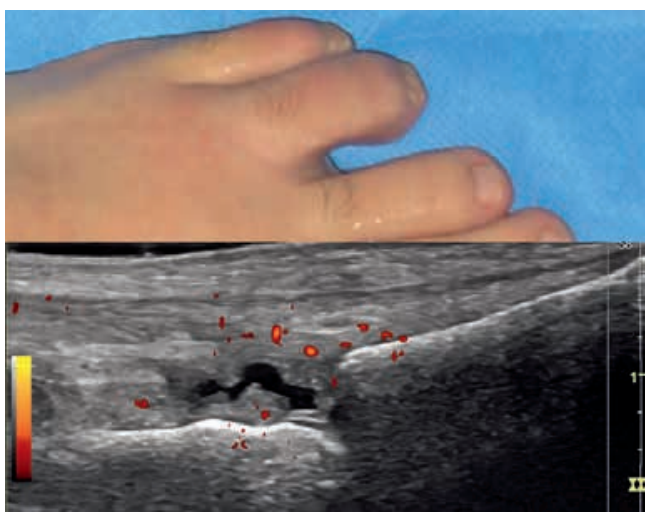

Fig 5. Longitudinal scan of the dorsal $4^{\text {th }}$ metacarpophalangeal (MTF) joint. A 36 years old man with psoriatic arthritis. The clinical aspect of dactylitis was realized by edema and MTF synovitis. No flexor tenosynovitis was found.

superficial layer to the deep ones. Nowadays, in soft tissue pathology examination is considered that US should be the first imaging technique to start with.

The aim of this pictorial essay is to describe the main US findings in non-traumatic lesions of the digits, diffuse or localized, inflammatory or tumoral. Most of the US pictures have been associated with the clinical aspect of the fingers in order to make more clearly the parallelism between clinical and imaging examinations.

\section{Diffuse lesions of the digits}

The main diffuse lesion of the digit (,the swollen digit") is dactylitis. The term of dactylitis is used to describe the inflammation of a finger or a toe. In clinical practice it is considered a hallmark feature of seronegative spondilarthropaties ( $\mathrm{SpA})$ especially of psoriatic arthritis [1]. The so-called „sausage-digit” appearance is created by „the uniform swelling, such that the soft tissues between the metacarpophalangeal and the proximal interphalangeal, proximal and distal interphalangeal, and/or distal interphalageal joint and digital tuft are diffusely swollen

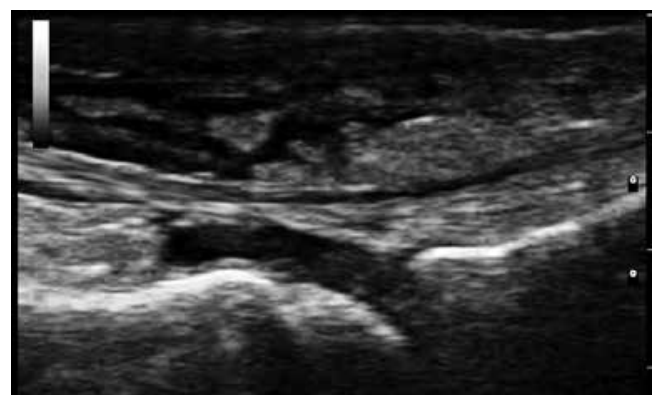

Fig 6. Longitudinal scan of the dorsal $2^{\text {nd }}$ metacarpophalangeal (MTF) joint in a 31 years old woman with seronegative spondilarthropatiy. The dactylitic aspect of the toe was produced mainly by subcutaneous edema. A small quantity of fluid was found in the MTF joint.

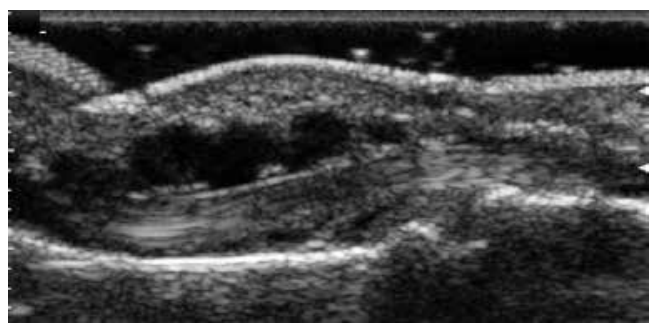

Fig 7. Longitudinal scan of the $2^{\text {nd }}$ finger. Dactylitis due to the flexor tendon tenosynovitis.

to the extent that the actual joint swelling could no longer be independently recognized" [2]. Dactylitis is considered to be so specific for SpA that it was included in the new criteria for the diagnosis of the whole disease group [3].

These changes are explained by various abnormalities. Olivieri et al showed that diffuse digital edema and inflammation of the digital flexor tendon sheats are the main cause of dactylitis in SpA [4]. Sometimes the enlargement of the digit joints contributes to the pathological aspect of the digit but the joint synovitis alone, without edema or flexor tenosynovitis can not give the „sausage-like” appearance [4-6] (fig 5-9) . These findings have also been confirmed by histopathological examinations in animal models [7]. Dactylitis can be characterized as acute (tender) or chronic (non-tender) [8].

In spite of the high specificity of dactylitis for SpA, the differential diagnosis should be careful considered. In tuberculosis dactylitis, the osteomyelitis of the short tubular bone of the hands and feet realizes the aspect of spina ventosa on the radiography. Syphilitic dactylitis (in congenital syphilis) is bilateral and symmetric. Blistering distal dactylitis (due to infection with group A be- 


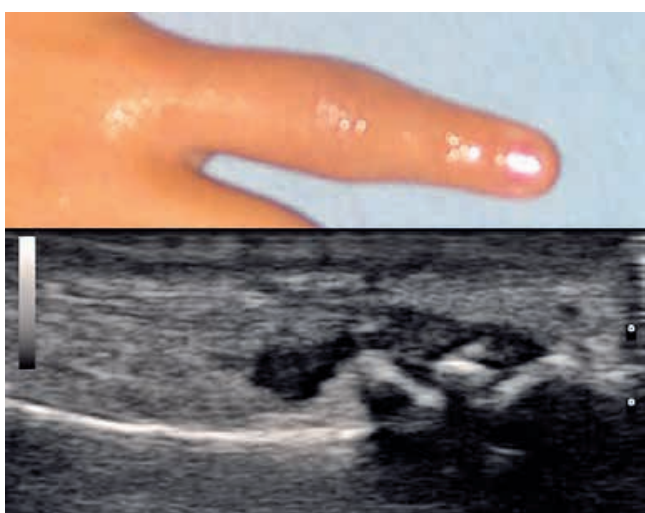

Fig 8. Dactylitis of the $2^{\text {nd }}$ finger in which the synovitis, bone contour irregularities (ostheophytes) of the proximal interphalangeal joint and edema had the main contribution to the clinical aspect. A 47 years old woman with psoriatic arthritis. Longitudinal dorsal scan.

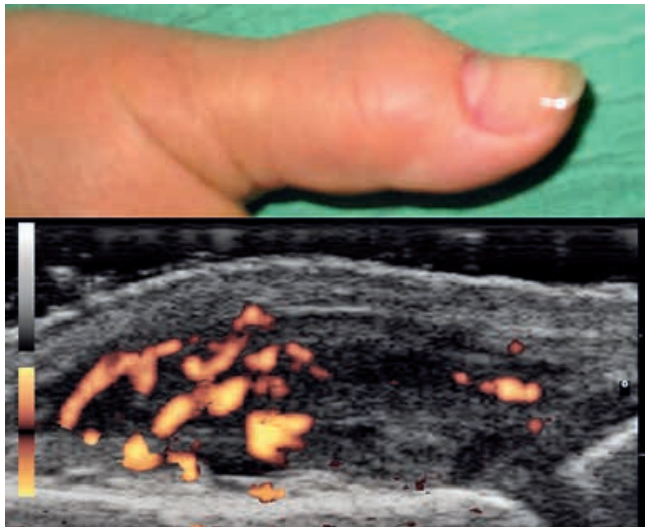

Fig 9. Clinical and US aspect of the thumb in a 56 years old woman with systemic erythematosus lupus. The hypervascularized synovitis of the interphalangeal joint was insufficient to produce the aspect of dactylitis.

ta-hemolytic Streptococcus or Staphylococcus aureus) involves the distal fat pad and it usually presents as a fluid-filled blister. The sickle cell dactylitis is due to bone marrow infarction, ("hand-foot syndrome"). Gouty dactylitis is a rare finding, seen in chronic polyarticular disease [2,5,9] (fig 10). Sarcoid dactylitis is a rare manifestation of sarcoidosis and tends to occur as the presenting symptom of the disease [9] (fig 11). The deposition of calcium pyrophosphate or uric acid crystals in the flexor tendon sheath of the hand was found to be a rare cause for a swollen finger [10] (fig 12). Differential diagnosis should be done also with local pathology as the presence of foreign body (fig 13, fig 14).

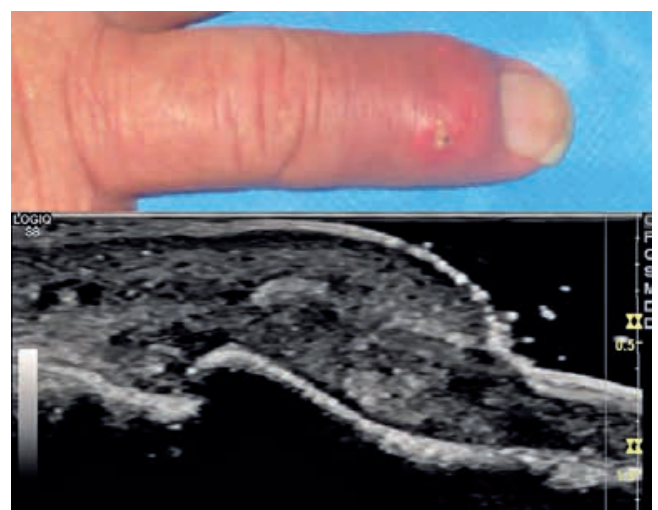

Fig 10. A 75 years old man with gout. Longitudinal dorsal scan of the $3^{\text {rd }}$ finger. swollen aspect of the distal region to the proximal interphalangeal joint due to diffuse deposition of the monosodium urate crystals deposition, even in the nail bed.

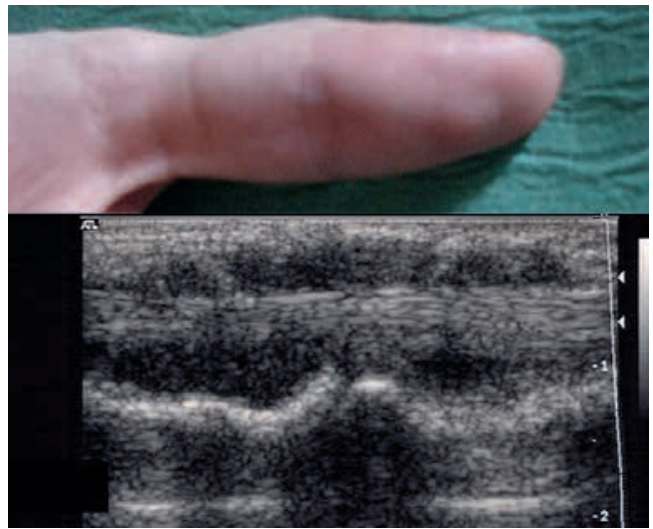

Fig 11. A 28 year-old woman with sarcoid dactylitis of the thumb produced by an important tenosynovitis of the flexor sheath. Some irregularities of bone contours of the interphalangeal joint were present, but no fluid or synovitis was found.

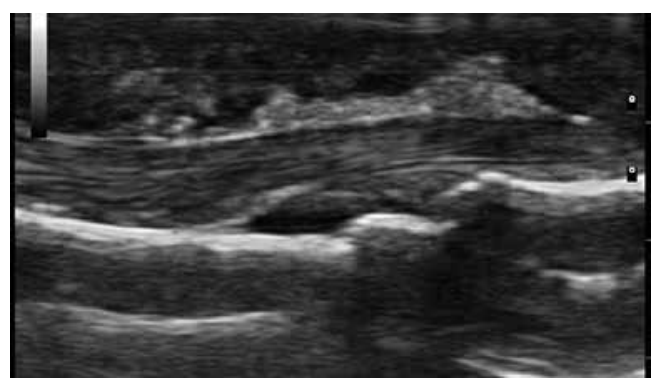

Fig 12. Calcium pyrophosphate deposition in the 3rd flexor tendon sheath (hyperechoic content of the sheath). The diagnosis was established after US guided aspiration of the sheath content and light polarized microscopy examination. 


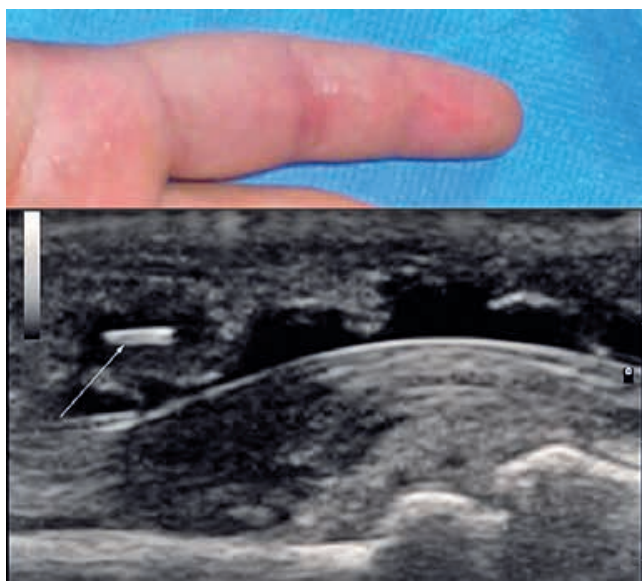

Fig 13. The dactylitic aspect of the 2nd finger due to a wood splinter (arrow) near the flexor tendon. Flexor tendon tenosynovitis was associated, explaining the clinical aspect of the finger.

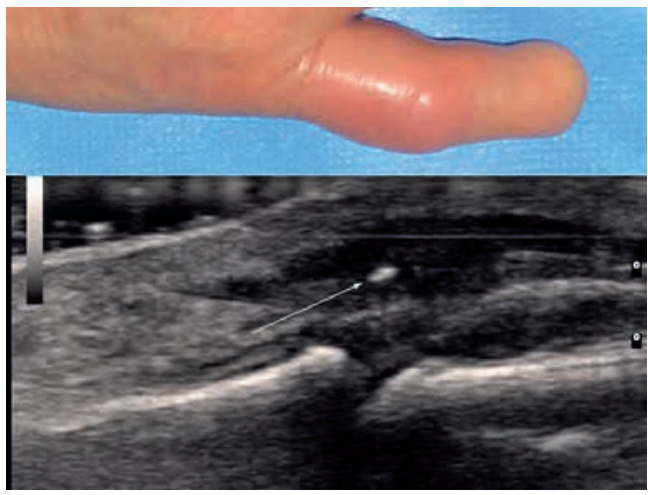

Fig 14. The presence of a thorn (arrow) near the proximal interphalangeal joint gives the clinical aspect of acute dactylitis mainly due to subcutaneous edema.

Tenosynovitis, defined as an hypoechoic or anechoic thickened tissue with or without fluid within the tendon sheath that is seen in two perpendicular planes and may exhibit Doppler signal [11], can be easily identified by US. Tendon sheath widening, visible in longitudinal and transverse planes, may be due to synovial hypertrophy (echoic pattern), to the presence of synovial fluid (anechoic pattern) or both (mixed pattern) - exudative or proliferative tenosynovitis. Also, the intraarticular synovial hypertrophy can be the reason for joint swelling. It is defined as an abnormal hypoechoic intra-articular tissue (compared with the subdermal fat, but sometimes found as isoechoic or hyperechoic) which is non displaceable, poorly compressible and may exhibit Doppler signal [11]. On the other hand, the presence of the synovial fluid (an abnormal hypoechoic or anechoic intra-articular

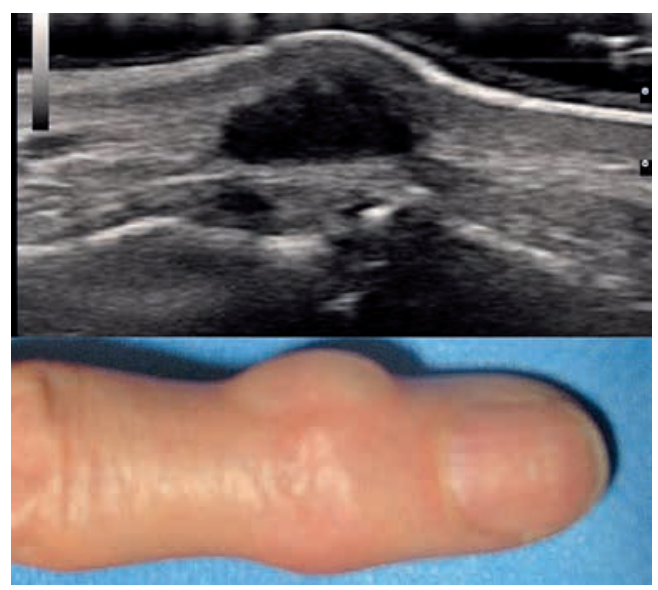

Fig 15. Ganglia cyst in the ulnar side of the distal interphalangeal joint of the index.

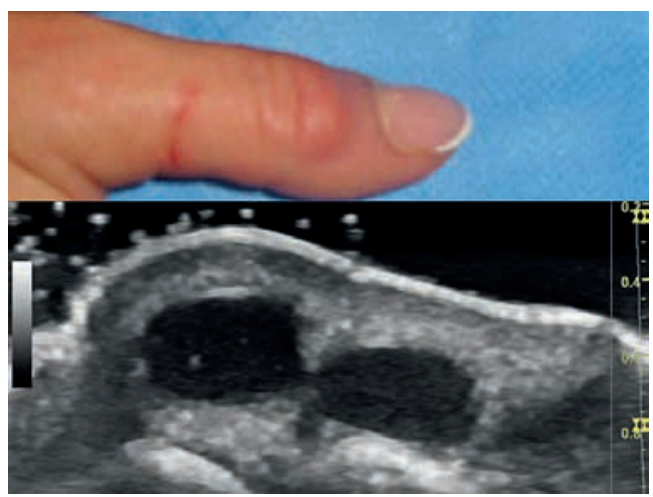

Fig 16. Bilobated ganglia cyst near the proximal interphalangeal joint of the thumb

material without Doppler signal that is displaceable and compressible with the transducer) [11] contributes to the pathological aspect of the joint.

\section{Localized lesions (masses) of the digits}

Localized masses of the digits can be characterized by US.

\section{Cysts}

Ganglia cyst is a well-defined structure with anechoic content and posterior enhancement. The most frequent site for ganglia is the base of the fingers, the third and the fourth fingers being commonly involved [12] (fig 15). A communicating duct to the joint space may be detected [13]. Not all the ganglia cysts are anechoic; hypoechoic or complex cysts (internal reflections, thick walls, septations 


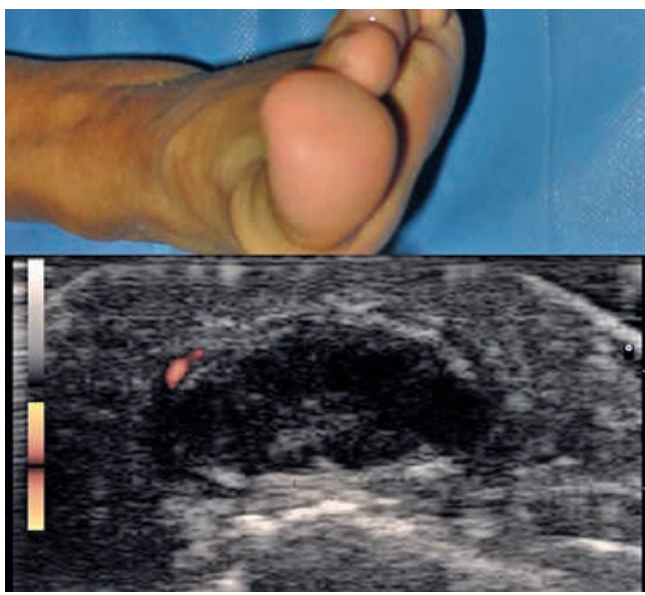

Fig 17. Hypoechoic ganglia cyst with thick walls in the distal phalanx of the big toe.

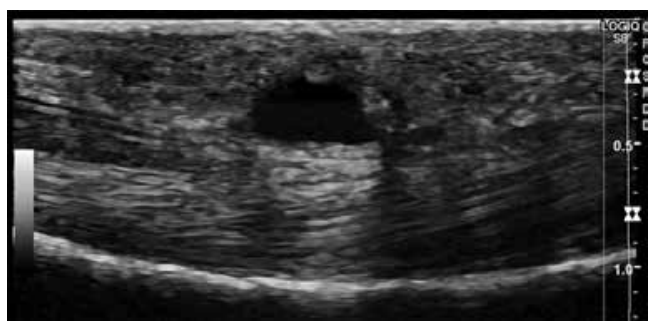

Fig 18. Flexor tendon sheath cysts, middle phalanx.

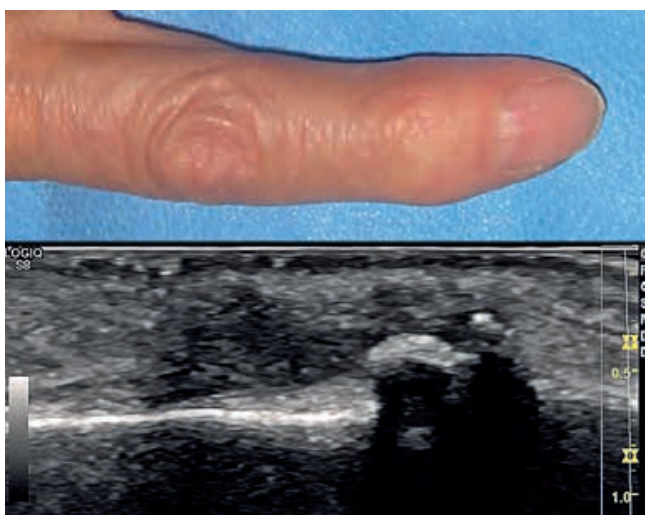

Fig 19. Mucous cysts in relation with the distal interphalangeal joint, associated with Heberden node

or locules) may be found [14] (fig 16, fig 17). The tendon sheath cysts generally can be mobilized with the tendon during the dynamic examination (fig 18). These types of lesions are the main etiology for the trigger finger.

Mucous cysts, well-defined hypoechoic lesions, in relation with the distal interphalangeal joint, frequently on its lateral side of the joint are part of the ostheoarthosis

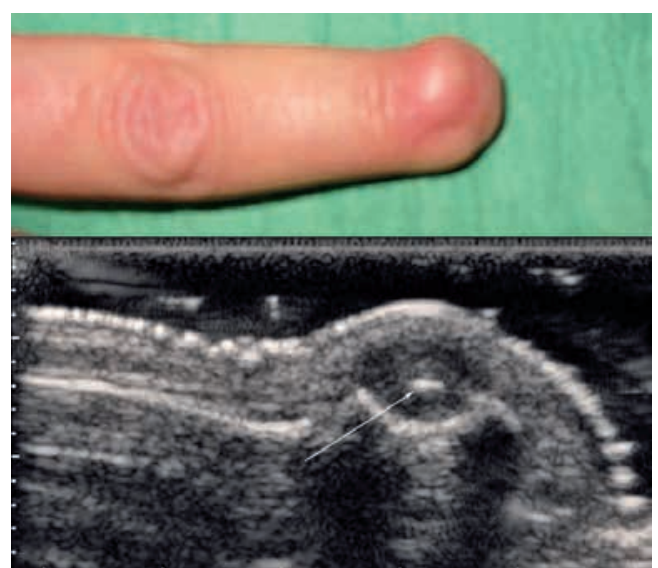

Fig 20. Postsurgery epidermal inclusion cyst. Note the hyperechoic internal structure (arrow) realized by epidermal elements.

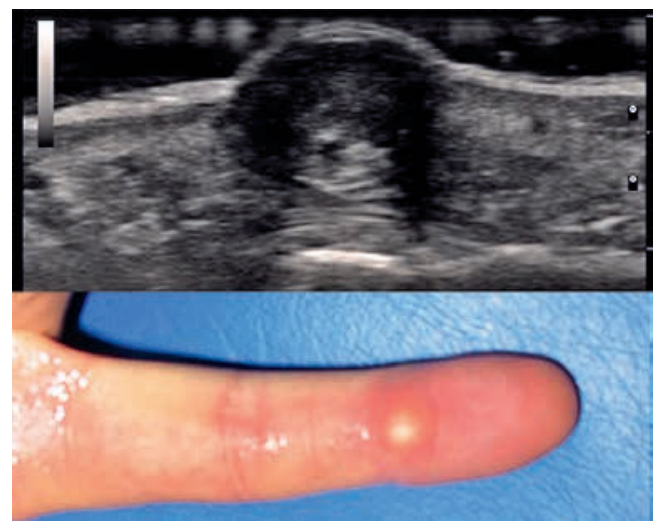

Fig 21. Giant cell tumor near the insertion of the flexor tendon in the distal phalanx

process and are associated with Heberden nodes [15] (fig 19). Epidermal inclusion cyst results from implantation of epidermis into the dermis, as in trauma or surgery (fig 20).

US is useful for cysts evaluation: the relation with the adjacent structure, size, localization, needle aspiration, and steroid injection.

Giant cell tumor of the tendon sheath (localized villonodular tenosynovitis) is a well-defined hypoechoic solid mass localized periarticular or paratendineous with increased internal flow in color Doppler examination (fig 21 ). Bone scalloping due to the pressure of the tumor on the underlying bone cortex can be demonstrated $[13,16]$. Generally the tumor is painless and the first three fingers of the right hand are more often affected [17].

Glomus tumor is a rare tumor derived from the glomus body found predominantly in the subungual region. 


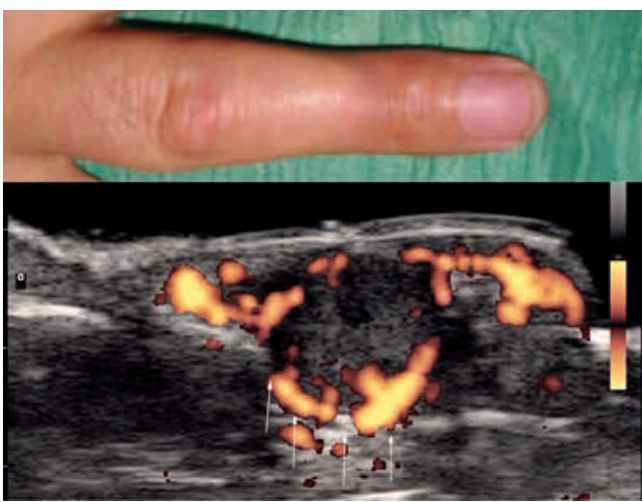

Fig 22. Glomus tumor in the subungual region. Note the scalloping of the bone cortex (arrows).

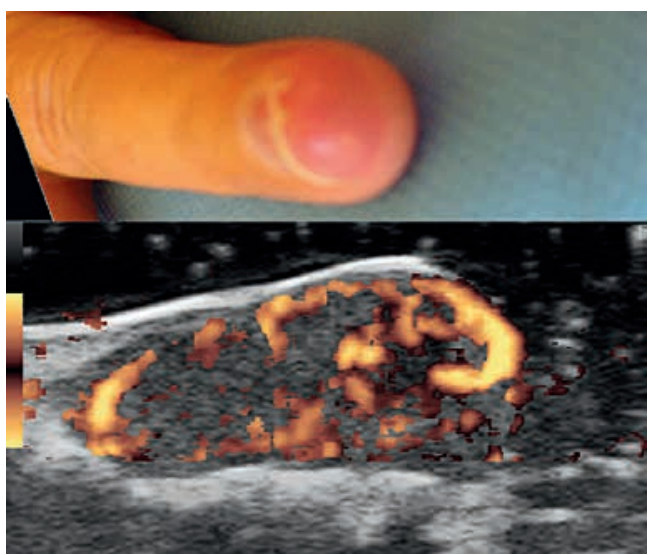

Fig 23. Large size glomus tumor with infiltrative growth into the bone suggestive for malignant tumor. Note the partial destruction of the nail.

The tumor is characterized by paroxysmal pain, sensitivity to cold, and severe point tenderness [18]. US reveals a hypoechoic solid mass highly vascularizated, situated in the nail bed, with the remodeling (scalloping) of the underlying bone [12,19] (fig 22). If the tumor displays unusual features, such as large size, deep location, or infiltrative growth a malignant glomus tumor should be considered [18] (fig 23).

Lipomas, fibrous tumor, and hemangiomas are rarely founded in digits; they occur mainly in the hand or foot. Clinical and US aspects are not different from other localizations

Nerve tumors (schwannomas and neurofibromas) rarely affect the hand or the foot and only exceptional affect the digits.

Soft malignant tumors are rare in the fingers. For bone tumors (benign or malignant) radiography, comput-

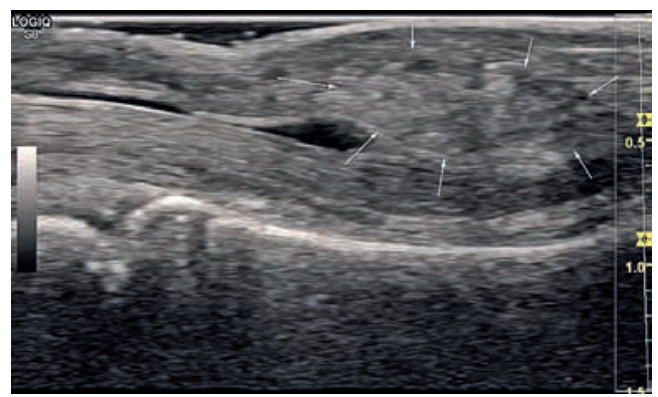

Fig 24. Soft tophus in the middle phalanx (arrows). Note the tenosynovitis of the flexor tendon.

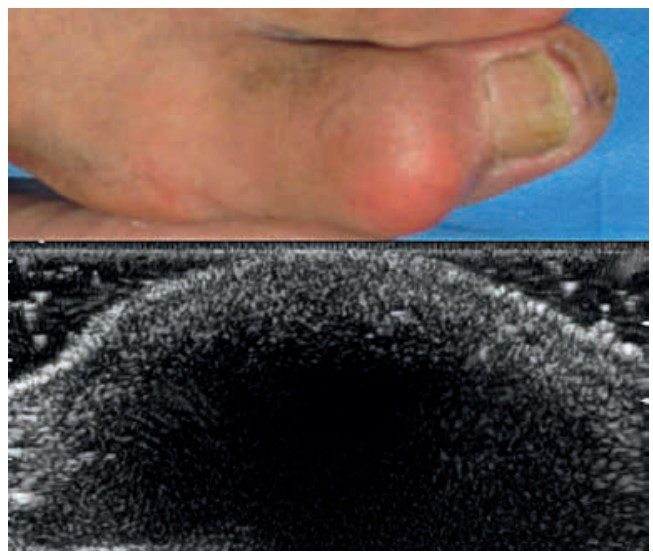

Fig 25. Hard tophus over the MTF I joint. The important posterior shadow does not permit the US evaluation of the deeper structures.

ed tomography, and magnetic resonance imaging studies are required.

Localized lesions of the fingers may also be represented by gouty tophi: hypoechoic, with homogenous structures and soft on palpation - soft tophi (fig 24) or pseudotumoral dishomogeneous structures, with important posterior shadow, rigid on palpation - firm or mixed tophi (fig 25), even with calcification foci [20]. In systemic forms of scleroderma the calcinosis can cause lumps under the fingers skin (fig 26) that may break through the skin and leak a white liquid similar with chalk.

In nail clubbing (Hippocratic fingers) the distortion of the distal phalanx and of the finger nails consists in increasing the convexity of the nail fold and the thickening of the whole distal phalanx, including the nail bed (fig 27). 


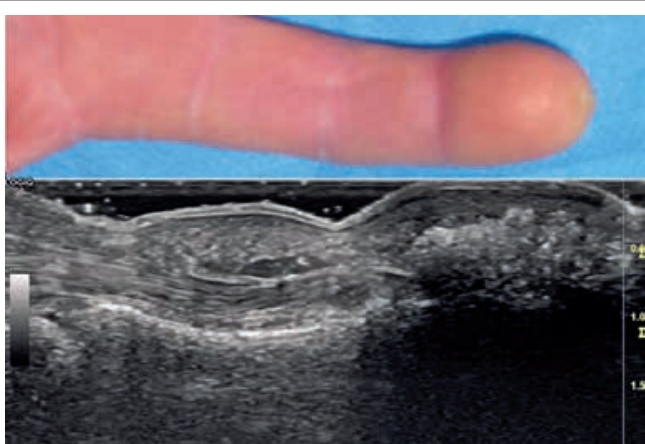

Fig 26. Calcinosis of the palmar side of the distal phalanx in a 51 years old woman with systemic scleroderma.

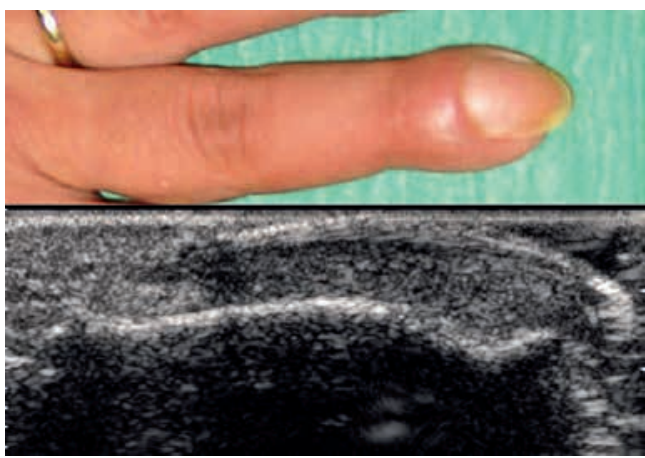

Fig 27. Nail clubbing (Hippocrates finger). Note the increasing convexity of the nail and thickening of the nail bed

\section{Conclusions}

US is an important tool for finger imaging examination being an established efficient, safe, cost-effective, and patient-friendly method to evaluate the structure of the normal and pathological digits. The high spatial resolution of the US gives important data to the clinician about the underlying process which produces a diffuse or localized modification in a finger. The method is useful for the clinician for taking decisions - concerning the optimal treatment, conservative or surgical - and for the follow up of the patient.

\section{Reference}

1. Amor B, Dougados M, Mijiyawa M. Criteria of the classification of spondylarthropathies. Rev Rhum Mal Osteoartic 1990; 57: 85-89.
2. Rothschild BM, Pingitore C, Eaton M. Dactylitis: implications for clinical practice. Semin Arthritis Rheum 1998; 28: 41-47.

3. Rudwaleit M, van der Heijde D, Landewé R, et al. The Assessment of SpondyloArthritis International Society classification criteria for peripheral spondyloarthritis and for spondyloarthritis in general. Ann Rheum Dis 2011; 70: 25-31.

4. Olivieri I, Padula A, Scarano E, Scarpa R. Dactylitis or "sausage-shaped" digit. J Rheumatol 2007; 34: 1217-1222.

5. Olivieri I, Scarano E, Padula A. Dactylitis, a term for different digit diseases. Scand J Rheumatol 2006; 35: 333-340.

6. Olivieri I, D'Angelo S, Scarano E, Padula A. What is the primary lesion in SpA dactylitis?Rheumatology (Oxford) 2008; 47: 561-562.

7. Lories RJU, Matthys P, de Vlam K, Luyten FP. Ankilosing enthesitis, dactylitis, and onychoperiostitis in male DBA/1 mice: a model of psoriatic arthritis. Ann Rheum Dis 2004 ; $63: 595-598$

8. Coates LC, Helliwell PS. Disease measurement-enthesitis, skin, nails, spine and dactylitis.Best Pract Res Clin Rheumatol 2010; 24: 659-670.

9. Healy PJ, Helliwell PS. Dactylitis: pathogenesis and clinical considerations. Curr Rheumatol Rep 2006; 8: 338-341.

10. Bullocks JM, Downey CR, Gibler DP, Netscher DT. Crystal deposition disease masquerading as proliferative tenosynovitis and its associated sequelae. Ann Plast Surg 2009; 62: 128-133.

11. Wakefield RJ, Balint PV, Szkudlarek M, et al. Musculoskeletal ultrasound including definitions for ultrasonographic pathology. J Rheumatol 2005; 32: 2485-2487.

12. Moschilla G, Breidahl W. Sonography of the finger. AJR Am J Roentgenol 2002; 178: 1451-1257.

13. Cheng JW, Tang SF, Yu TY, Chou SW, Wong AM, Tsai WC. Sonographic features of soft tissue tumors in the hand and forearm. Chang Gung Med J 2007; 30: 547-554.

14. Teefey SA, Dahiya N, Middleton WD, Gelberman RH, Boyer MI. Ganglia of the hand and wrist: a sonographic analysis. AJR Am J Roentgenol 2008; 191: 716-720.

15. Meenagh G, Filippucci E, Iagnocco A, et al. Ultrasound imaging for the rheumatologist VIII. Ultrasound imaging in osteoarthritis. Clin Exp Rheumatol 2007; 25: 172-175.

16. Garcia J, Bianchi S. Diagnostic imaging of tumors of the hand and wrist. Eur Radiol 2001; 11: 1470-1482.

17. Monaghan H, Salter DM, Al-Nafussi A. Giant cell tumour of tendon sheath (localised nodular tenosynovitis): clinicopathological features of 71 cases. J Clin Pathol 2001: 54: 404-407.

18. Smalberger GJ, Suszko JW, Khachemoune A. Painful growth on right index finger. Subungual glomus tumor. Dermatol Online J 2011; 17:12.

19. Wortsman X, Jemec GB. Role of high-variable frequency ultrasound in preoperative diagnosis of glomus tumors: a pilot study. Am J Clin Dermatol 2009; 10: 23-27.

20. Delle Sedie A, Riente L, Iagnocco A, et al. Ultrasound imaging for the rheumatologist $\mathrm{X}$. Ultrasound imaging in crystal-related arthropathies. Clin Exp Rheumatol 2007; 25: 513-517. 